\title{
Characteristics and outcomes of asthmatic patients with COVID-19 pneumonia who require hospitalisation
}

\author{
Antoine Beurnier ${ }^{1,2,3}$, Etienne-Marie Jutant ${ }^{1,2,4}$, Mitja Jevnikar ${ }^{1,2,4}$, \\ Athénaïs Boucly ${ }^{1,2,4}$, Jérémie Pichon ${ }^{1,2,4}$, Mariana Preda ${ }^{1,2,4}$, Marie Frank ${ }^{5}$, \\ Jérémy Laurent ${ }^{5}$, Christian Richard ${ }^{1,6}$, Xavier Monnet ${ }^{1,6}$, Jacques Duranteau ${ }^{1,7}$, \\ Anatole Harrois ${ }^{1,7}$, Marie-Camille Chaumais ${ }^{1,2,8}$, Marie-France Bellin ${ }^{1,9}$, \\ Nicolas Noël ${ }^{1,10}$, Sophie Bulifon ${ }^{1,2,4}$, Xavier Jaïs ${ }^{1,2,4}$, Florence Parent ${ }^{1,2,4}$, \\ Andrei Seferian ${ }^{1,2,4}$, Laurent Savale (11) ${ }^{1,2,4}$, Olivier Sitbon (10 ${ }^{1,2,4}$, \\ David Montani (10 ${ }^{1,2,4}$ and Marc Humbert (10 $1,2,4$
}

@ERSpublications

Asthmatic patients were not overrepresented among those with severe pneumonia due to SARS-CoV-2 infection who required hospitalisation. None presented with an asthma exacerbation. Worst outcomes were observed mainly in patients with major comorbidities. https://bit.ly/303djG6

Cite this article as: Beurnier A, Jutant E-M, Jevnikar M, et al. Characteristics and outcomes of asthmatic patients with COVID-19 pneumonia who require hospitalisation. Eur Respir J 2020; 56: 2001875 [https:// doi.org/10.1183/13993003.01875-2020].

\section{ABSTRACT}

Background: Viral respiratory infections are the main causes of asthma exacerbation. The susceptibility of patients with asthma to develop an exacerbation when they present with severe pneumonia due to severe acute respiratory syndrome coronavirus 2 (SARS-CoV-2) infection is unknown. The objective of this study was to investigate the characteristics and outcomes of asthmatic patients with coronavirus disease 2019 (COVID-19) pneumonia who required hospitalisation during the spring 2020 outbreak in Paris, France. Methods: A prospective cohort follow-up was carried out from 15 March to 15 April 2020 in Bicêtre Hospital, University Paris-Saclay, France. All hospitalised patients with a SARS-CoV-2 infection who reported a history of asthma were included.

Results: Among 768 hospitalised patients, 37 (4.8\%) reported a history of asthma, which had been previously confirmed by a pulmonologist in $85 \%$ of cases. These asthmatic patients were mainly female (70\%) and nonsmokers (85\%), with a median age of 54 years (interquartile range (IQR) 42-67 years). None of them presented with an asthma exacerbation. 22 (59\%) had major comorbidities and 31 (84\%) had a body mass index $\geqslant 25 \mathrm{~kg} \cdot \mathrm{m}^{-2}$. The most common comorbidities were obesity ( $\left.36 \%\right)$, hypertension (27\%) and diabetes (19\%). All patients had a confirmed diagnosis of COVID-19 pneumonia on computed tomography of the chest. Eosinopenia was a typical biological feature with a median count of 0 cells $\cdot \mathrm{mm}^{-3}$ (IQR $0-0$ cells $\cdot \mathrm{mm}^{-3}$ ). 11 patients $(30 \%)$ were admitted into the intensive care unit, with three deaths $(8.1 \%)$ occurring in the context of comorbidities.

Conclusion: Asthma patients were not overrepresented among those with severe pneumonia due to SARSCoV-2 infection who required hospitalisation. The worst outcomes were observed mainly in patients with major comorbidities.

This article has supplementary material available from erj.ersjournals.com

Received: 19 May 2020 | Accepted after revision: 18 July 2020

Copyright OERS 2020. This version is distributed under the terms of the Creative Commons Attribution NonCommercial Licence 4.0. 


\section{Introduction}

Viral respiratory infections are the main causes of asthma exacerbations in both adults and children. Coronaviruses are commonly isolated in the respiratory tract of these patients [1]. As the world faces the coronavirus disease 2019 (COVID-19) pandemic due to severe acute respiratory syndrome coronavirus 2 (SARS-CoV-2) infection, concerns have arisen about a possible increased risk of asthma exacerbations. Indeed, SARS-CoV-2 is well known for its respiratory tropism that can lead to severe pneumonia and potentially fatal acute respiratory distress syndrome (ARDS) [2]. However, the prevalence of asthma among inpatients with COVID-19 remains debated. In Wuhan, China, Li et al. [3] pointed out a rate of $0.9 \%$, markedly lower than that in the local population; in another study investigating the clinical characteristics and allergy status of 140 patients infected by SARS-CoV-2 in Wuhan, no patients were reported as being asthmatic [4]. Conversely, Goyal et al. [5] found that asthmatic patients accounted for $12.5 \%$ of total COVID-19 inpatients in New York. Beside these conflicting statistics, the characteristics and the outcomes of asthmatic patients infected with SARS-CoV-2 have not yet been described in detail.

In France, the Great Paris region (Ile-de-France) has been particularly affected by the epidemic. On 14 March 2020, the Regional Health Agency issued a statement underscoring the rapid spread of SARS-CoV-2 in the region with 376 new daily confirmed cases [6]; the number of regional hospitalisations for COVID-19 eventually reached a peak on 1 April 2020 [7]. From 15 March to 15 April 2020 we carried out a prospective study in Bicêtre Hospital, University Paris-Saclay, France. The objective of this study was to investigate the characteristics and outcomes of asthmatic patients with COVID-19 pneumonia who required hospitalisation.

\section{Material and methods \\ Patients and study design}

A prospective monocentric cohort follow-up was initiated in Bicêtre Hospital, France. All adult patients hospitalised from 15 March to 15 April 2020 with a diagnosis of SARS-CoV-2 infection and reporting a history of asthma were included. The decision about hospitalisation was based on a concerted decision algorithm that has been locally implemented into clinical practice during the French COVID-19 outbreak (supplementary figure S1). COVID-19 was first suspected on the basis of compatible symptoms: in suspected cases, both SARS-CoV-2 reverse transcription (RT)-PCR on nasopharyngeal swab and computed tomography (CT) of the chest were systematically performed. Diagnosis was confirmed in the presence of positive SARS-CoV-2 RT-PCR and/or typical CT abnormalities (i.e. ground-glass opacities and/or consolidation in the lung periphery) [8]. A random control group of 75 non-asthmatic patients hospitalised for COVID-19 pneumonia in our hospital during the same period was also included and analysed. Patients received written information about data collection. After inclusion, all data regarding the clinical status, main outcomes, and biological and radiological features were recorded in an anonymous database registered to the National Commission on Informatics and Liberty (number 2217978).

\section{Characteristics at diagnosis and outcomes}

The following data were collected after patient-centred interviews: comorbid conditions (obesity, hypertension, diabetes, renal failure, coronary heart disease); current smoking status ("nonsmokers" referring to both former and never-smokers); history of asthma; and asthma controller treatment, with classification from step 1 to 5 according to the last 2020 Global Initiative for Asthma (GINA) report [9]. When feasible, we also clarified with the patient or their family whether asthma diagnosis had been confirmed by a pulmonologist or not. In addition, the following laboratory tests were analysed at admission: SARS-CoV-2 RT-PCR result, blood count, cardiac biomarkers, liver function, arterial blood gas, C-reactive protein (CRP), fibrinogen, D-dimers, creatine phosphokinase, lactate dehydrogenase (LDH) and ferritin. CT of the chest was analysed by a radiologist and a pulmonologist and the extent of lesions was classified as mild $(<10 \%)$, moderate $(10-24 \%)$, severe $(25-49 \%)$, very severe $(50-74 \%)$ or critical

Affiliations: 'Université Paris-Saclay, Faculty of Medicine, Le Kremlin-Bicêtre, France. ${ }^{2}$ INSERM UMR_S 999. Le Kremlin-Bicêtre, France. ${ }^{3}$ AP-HP, Service de physiologie et d'explorations fonctionnelles respiratoires (CRISALIS/F-CRIN network), Hôpital Bicêtre, Le Kremlin-Bicêtre, France. ${ }^{4}$ AP-HP, Service de pneumologie et soins intensifs respiratoires, Hôpital Bicêtre, Le Kremlin-Bicêtre, France. ${ }^{5}$ AP-HP, Département d'information médicale, Hôpital Bicêtre, Le Kremlin-Bicêtre, France. ${ }^{6} \mathrm{AP}-\mathrm{HP}$, Service de médecine intensive-réanimation, Hôpital Bicêtre, Le Kremlin-Bicêtre, France. ${ }^{7} \mathrm{AP}-\mathrm{HP}$, Département d'anesthésie et réanimation, Hôpital Bicêtre, Le Kremlin-Bicêtre, France. ${ }^{8}$ AP-HP, Service de pharmacie, Hôpital Bicêtre, Le Kremlin-Bicêtre, France. ${ }^{9}$ AP-HP, Service d'imagerie médicale, Hôpital Bicêtre, Le Kremlin-Bicêtre, France. ${ }^{10}$ AP-HP, Service de médecine interne, Hôpital Bicêtre, Le Kremlin-Bicêtre, France.

Correspondence: Marc Humbert, Dept of Respiratory and Intensive Care Medicine, Hôpital Bicêtre, 78 rue du général Leclerc, 94270 Le Kremlin-Bicêtre, France. E-mail: marc.humbertđaphp.fr 
$(\geqslant 75 \%)$. The following management strategies were detailed: use of systemic corticosteroids, short-acting $\beta$-agonists (SABAs) and/or antibiotics; adjustment of asthma controller; and requirement for oxygen supplementation, intensive care unit (ICU) admission and/or mechanical ventilation. Finally, the main outcomes (mortality, length of ICU stay and total length of hospital stay) were investigated after a 1-month follow-up.

\section{Statistical methods}

Quantitative data were expressed as median (interquartile range (IQR)), with the IQR presented as first quartile to third quartile. Qualitative data were expressed as number of occurrences, i.e. $\mathrm{n}$ (\%). Where there were missing data, the number of patients with available information was provided for each variable. When this number was not specified, the data of the entire population were available and analysed. To compare the continuous variables between two groups, a t-test or a Mann-Whitney U-test (if not normally distributed) was used. Pearson's Chi-squared test or Fisher's exact test, as appropriate, was used to compare discrete variables between two groups.

\section{Results}

Clinical characteristics of patients hospitalised for COVID-19 pneumonia

Among 768 hospitalised COVID-19 patients, 37 (4.8\%) reported a history of asthma. 31 asthmatic patients $(84 \%)$ had positive SARS-CoV-2 RT-PCR on nasopharyngeal swab. The remaining six were diagnosed on the basis of clinical presentation and radiological patterns [8].

Asthmatic patients were mainly female (70\%) and nonsmokers (85\%), with a median (IQR) age of 54 (4267 ) years and a median (IQR) body mass index (BMI) of $28.3(26.8-31.5) \mathrm{kg} \cdot \mathrm{m}^{-2}$. In $85 \%$ of cases, the diagnosis of asthma had been previously confirmed by a pulmonologist. 11 patients (30\%) were GINA step 5 , receiving high doses of inhaled corticosteroids (ICS) with long-acting $\beta$-agonists (LABAs), associated with low-dose oral corticosteroids in one case, and long-term omalizumab therapy in two cases (supplementary table S1). 31 asthmatic patients (84\%) had a BMI $\geqslant 25 \mathrm{~kg} \cdot \mathrm{m}^{-2} .22(59 \%)$ had at least one major comorbidity. The most common comorbid conditions were obesity (36\%), hypertension (27\%) and diabetes (19\%). 15 (41\%) had multiple comorbidities (table 1).

The median (IQR) time from onset of symptoms to admission to the emergency room was 6 (3-8) days. $50 \%$ of patients had an initial peripheral oxygen saturation $<95 \%$ while breathing room air, and $25 \%$ had a

\begin{tabular}{|c|c|c|c|}
\hline Characteristics & Asthmatic & Control & p-value \\
\hline Patients n & 37 & 75 & \\
\hline Age years & $54(42-67)$ & $60(52-70)$ & $0.019 *$ \\
\hline Male/female & $11(30) / 26(70)$ & $49(65) / 26(35)$ & $<0.001 *$ \\
\hline $\mathrm{BMI} \mathrm{kg} \cdot \mathrm{m}^{-2}$ & $28.3(26.8-31.5)$ & $28.7(26.8-31.2)^{\#}$ & 0.856 \\
\hline \multicolumn{4}{|l|}{ Tobacco exposure } \\
\hline Current/former smokers & $12(32)$ & $18(24)$ & 0.343 \\
\hline Never-smokers & $25(68)$ & $57(76)$ & 0.343 \\
\hline \multicolumn{4}{|l|}{ Comorbid conditions } \\
\hline Obesity & $13(36)$ & $24(37)^{\#}$ & 0.901 \\
\hline Class I $(30 \leqslant \mathrm{BMI}<35)$ & 5 & 17 & \\
\hline Class II $(35 \leqslant \mathrm{BMI}<40)$ & 6 & 4 & \\
\hline Class III $(B M I \geqslant 40)$ & 2 & 3 & \\
\hline Overweight $(25 \leqslant \mathrm{BMI}<30)$ & $18(49)$ & $35(54)^{\#}$ & 0.613 \\
\hline Hypertension & $10(27)$ & $32(43)$ & 0.161 \\
\hline Diabetes & 7 (19) & $17(23)$ & 0.834 \\
\hline Renal failure & $3(8)$ & $6(8)$ & 1.000 \\
\hline Dialysis & 2 & 3 & \\
\hline Nephrectomy & 1 & 0 & \\
\hline Coronary heart disease & $2(5)$ & $6(8)$ & 1.000 \\
\hline At least two of the six comorbidities & $15(41)$ & $35(52)^{\pi}$ & 0.253 \\
\hline
\end{tabular}

Data are presented as median (interquartile range) or $\mathrm{n}(\%)$, unless otherwise stated. The interquartile range is presented as first quartile - third quartile. For variables with missing data, the number of patients with available information is specified. BMI: body mass index. ${ }^{\#}: n=65 ;{ }^{\uparrow}: n=67 ;{ }^{*}: p<0.05$. 
TABLE 2 Clinical features at presentation to the emergency room

\begin{tabular}{|c|c|c|c|c|c|}
\hline \multirow[t]{2}{*}{ Variable } & \multicolumn{2}{|c|}{ Asthmatic } & \multicolumn{2}{|c|}{ Control } & \multirow[t]{2}{*}{ p-value } \\
\hline & Data & $\begin{array}{c}\text { Patients } \\
\mathbf{n}\end{array}$ & Data & $\begin{array}{c}\text { Patients }^{\#} \\
\text { n }\end{array}$ & \\
\hline $\begin{array}{l}\text { Time since onset of symptoms } \\
\text { days }\end{array}$ & $6(3-8)$ & 37 & $7(3-10)$ & 75 & 0.239 \\
\hline Systolic blood pressure mmHg & 132 (123-145) & 36 & $138(122-151)$ & 73 & 0.457 \\
\hline Diastolic blood pressure $\mathrm{mmHg}$ & $81(71-89)$ & 36 & 79 (69-88) & 73 & 0.993 \\
\hline Heart rate beats $\cdot \min ^{-1}$ & $99(88-111)$ & 36 & $100(89-109)$ & 73 & 0.714 \\
\hline Temperature ${ }^{\circ} \mathrm{C}$ & $38.1(37.3-38.7)$ & 36 & $38.2(27.4-38.7)$ & 74 & 0.899 \\
\hline Respiratory rate breaths $\cdot \min ^{-1}$ & $26(20-30)$ & 31 & $28(20-32)$ & 62 & 0.361 \\
\hline $\mathrm{S}_{\mathrm{pO}_{2}}$ while breathing room air $\%$ & $95(92-97)$ & 35 & 93 (89-95) & 71 & $0.008^{*}$ \\
\hline Wheezing & $6(16)$ & 37 & $2(3)$ & 75 & $0.015^{*}$ \\
\hline Mild wheezing & 5 & 37 & 0 & 75 & \\
\hline Severe wheezing & 1 & 37 & 2 & 75 & \\
\hline
\end{tabular}

Data are presented as median (interquartile range) or $\mathrm{n}(\%)$, unless otherwise stated. The interquartile range is presented as first quartile - third quartile. $\mathrm{S}_{\mathrm{pO}_{2}}$ : peripheral oxygen saturation. ${ }^{\#}$ : patients with available information. *: $p<0.05$.

respiratory rate $>30$ breaths $\cdot \mathrm{min}^{-1}$. None of the patients presented with an asthma exacerbation. Wheezing, mostly reported as mild, was reported at admission in only six cases (16\%) (table 2).

Non-asthmatic controls are presented in tables 1 and 2. All differences pointed to worse COVID-19 pneumonia in non-asthmatic patients, as evidenced by older age, higher male/female rate, and a trend to more comorbidities.

Biological findings at inclusion

Laboratory values in the emergency room are summarised in table 3. Among asthmatic patients, lymphopenia was a frequent finding (median (IQR) lymphocytes 1205 (738-1475) cells. $\mathrm{mm}^{-3}$ (figure 1a).

TABLE 3 Laboratory results at diagnosis

\begin{tabular}{|c|c|c|c|c|c|}
\hline \multirow[t]{2}{*}{ Variable } & \multicolumn{2}{|c|}{ Asthmatic } & \multicolumn{2}{|l|}{ Control } & \multirow[t]{2}{*}{ p-value } \\
\hline & Data & Patients ${ }^{\#} \mathrm{n}$ & Data & Patients $^{\#} \mathrm{n}$ & \\
\hline Leukocytes cells $\cdot \mathrm{mm}^{-3}$ & 6990 (5710-9020) & 37 & 6690 (5330-9483) & 74 & 0.719 \\
\hline Platelets cells $\cdot \mathrm{mm}^{-3}$ & $213000(159000-239000)$ & 37 & $206000(165000-254000)$ & 74 & 0.699 \\
\hline Neutrophils cells $\cdot \mathrm{mm}^{-3}$ & $5225(2835-6910)$ & 36 & 5160 (3815-7698) & 74 & 0.883 \\
\hline Eosinophils cells $\cdot \mathrm{mm}^{-3}$ & $0(0-0)$ & 36 & $0(0-0)$ & 74 & 0.254 \\
\hline D-dimers $\mu \mathrm{g} \cdot \mathrm{L}^{-1}$ & $810(483-1180)$ & 34 & $1080(680-1508)$ & 64 & 0.329 \\
\hline CRP $\mathrm{mg} \cdot \mathrm{L}^{-1}$ & $51(27-116)$ & 37 & $86(51-174)$ & 75 & $0.040 *$ \\
\hline LDH IU:L ${ }^{-1}$ & $283(235-359)$ & 31 & $392(311-512)$ & 66 & $0.005^{*}$ \\
\hline CPK IU.L ${ }^{-1}$ & $100(62-160)$ & 33 & $189(84-390)$ & 71 & 0.245 \\
\hline ASAT IU.L ${ }^{-1}$ & $38(25-62)$ & 33 & 51 (39-73) & 69 & $0.022^{*}$ \\
\hline ALAT IU:L ${ }^{-1}$ & $30(23-47)$ & 34 & $37(27-64)$ & 71 & 0.058 \\
\hline$P_{\mathrm{aO}_{2}}$ in room air $\mathrm{mmHg}$ & $68(62-83)$ & 29 & $63(52-74)$ & 61 & $0.010^{*}$ \\
\hline$P_{\mathrm{acO}_{2}}$ in room air $\mathrm{mmHg}$ & $34(32-38)$ & 29 & $35(32-38)$ & 61 & 0.762 \\
\hline
\end{tabular}

Data are presented as median (interquartile range), unless otherwise stated. The interquartile range is presented as first quartile - third quartile. CRP: C-reactive protein; LDH: lactate dehydrogenase; CPK: creatine phosphokinase; ASAT: aspartate transaminase; ALAT: alanine aminotransferase; troponin T HS: high-sensitive cardiac troponin T; NT-proBNP: N-terminal pro-brain natriuretic peptide; $P_{\mathrm{aO}_{2}}$ : arterial oxygen tension; $P_{\mathrm{aCO}}$ : arterial carbon dioxide tension. ${ }^{\#}$ : patients with available information. ${ }^{*}$ : $p<0.05$. 

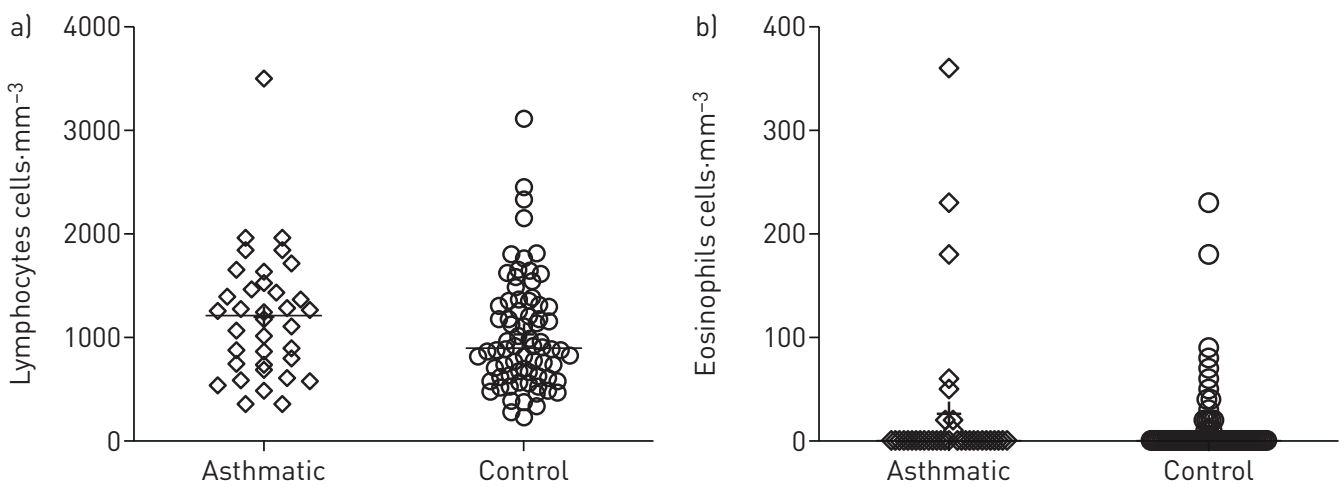

FIGURE 1 Blood counts of a) lymphocytes and b) eosinophils, at admission, for asthmatic and control patients.

Patients also presented with a marked eosinopenia, 78\% having a blood eosinophil count equal to zero (figure $1 \mathrm{~b}$ ). N-terminal pro-brain natriuretic peptide was measured in 21 patients and normal values $\left(<300 \mathrm{ng} \cdot \mathrm{L}^{-1}\right)$ were found in $81 \%$ of cases. Of 31 with available data, six patients $(19 \%)$ had increased high-sensitive cardiac troponin $\mathrm{T}\left(\geqslant 14 \mathrm{ng} \cdot \mathrm{L}^{-1}\right)$; however, none of these patients demonstrated consistent evidence of serious myocardial injury. Elevation of D-dimers was commonly observed (median (IQR) 810 $\left.(483-1180) \mu \mathrm{g} \cdot \mathrm{L}^{-1}\right)$, as well as increased CRP levels (median (IQR) $\left.51(27-116) \mathrm{mg} \cdot \mathrm{L}^{-1}\right)$. Arterial blood gas while breathing room air was available in 29 patients: hypoxaemia was a common finding (median (IQR) arterial oxygen tension $68(62-83) \mathrm{mmHg}$ ) with hypocapnia (median (IQR) arterial carbon dioxide tension 34 (32-38) $\mathrm{mmHg}$ ).

Non-asthmatic controls are presented in table 3. There was a trend for more pronounced lymphopenia and worse CRP, D-dimer, LDH and liver transaminases levels, with more severe hypoxaemia.

\section{Radiological findings}

All asthmatic patients underwent CT of the chest (table 4). Peripheral or mixed ground-glass opacities were the most frequent CT patterns (95\% of cases), expanding over $>10 \%$ of lung parenchyma in $76 \%$ of cases. Consolidations were observed in 26 patients (70\%) and crazy-paving pattern in 13 patients (35\%). In $51 \%$ of cases, lesions predominated in inferior lobes. Based on clinical judgement or prediction rules [10], four patients had initial CT pulmonary angiography (CTPA), demonstrating two cases of acute pulmonary embolisms at admission. Eight additional CTPA scans were performed during hospital stays to investigate

\section{TABLE 4 Computed tomography of the chest: features of COVID-19 pneumonia}

\begin{tabular}{lccc} 
Variable & Asthmatic & Control & p-value \\
\hline Patients n & 37 & $66^{\#}$ & \\
Ground-glass opacities & $36(97)$ & $64(97)$ & 1.000 \\
Consolidations & $26(70)$ & $56(85)$ & 0.132 \\
Lower lobe predominance & $19(51)$ & $44(67)$ & 0.187 \\
Crazy paving & $13(38)$ & $30(45)$ & 0.453 \\
Topography & & $39(59)$ & 0.971 \\
$\quad$ Peripheral & $22(59)$ & $1(2)$ & 1.000 \\
Central & $1(3)$ & $26(39)$ & 0.876 \\
Mixed & $14(38)$ & & \\
Lesion extent & $9(24)$ & $18(27)$ & $0.035^{*}$ \\
$\quad$ Mild (<10\%) & $15(41)$ & $31(47)$ & 0.166 \\
Moderate (10-25\%) & $11(30)$ & $10(16)$ & 0.088 \\
Severe (25-50\%) & $1(3)$ & $1(1)$ & $0.050^{*}$ \\
Very severe (50-75\%) & $1(3)$ & $24(36)$ & 1.000 \\
Critical (>75\%) & $24(65)$ & $42(64)$ & $0.005^{*}$ \\
Mild-to-moderate & $13(35)$ & & $0.005^{*}$ \\
Severe-to-critical & & & \\
\hline
\end{tabular}

Data are presented as $\mathrm{n}(\%)$, unless otherwise stated. ${ }^{\#}$ : patients with available information; there were 75 control patients in total. 


\begin{tabular}{|c|c|c|}
\hline Management & Treatment received & $\begin{array}{c}\text { Patients } \\
\text { n }\end{array}$ \\
\hline Oxygen & $30(81)$ & 37 \\
\hline Antibiotic(s) & $31(84)$ & 37 \\
\hline Azithromycin & $16(52)$ & 37 \\
\hline $\begin{array}{l}\text { Intravenous or oral corticosteroids for asthma exacerbation during } \\
\text { hospitalisation }\end{array}$ & 1 (3) & 37 \\
\hline SABA prescription & $31(86)$ & 36 \\
\hline pMDI plus spacer chamber & $29(81)$ & 36 \\
\hline DPI & $2(6)$ & 36 \\
\hline Nebulised & $4(11)$ & 36 \\
\hline \multicolumn{3}{|l|}{ Asthma controller treatment adjustment } \\
\hline Maintenance & $33(94)$ & 35 \\
\hline Stepped up & $1(3)$ & 35 \\
\hline
\end{tabular}

Data are presented as $n(\%)$, unless otherwise stated. SABA: short-acting $\beta$-agonist; pMDI: pressurised metered-dose inhaler; DPI: dry powder inhaler. ${ }^{\#}$ : patients with available information.

clinical deterioration, leading to another acute pulmonary embolism diagnosis. In this small cohort of patients, higher ICS exposure was not associated with a higher proportion of severe radiological pneumonia; mild pneumonia tended to be more frequent in asthmatic patients with higher doses of ICS (supplementary figure S2).

All non-asthmatic controls had imaging of the chest at admission (66 CT and nine chest radiography). The results of CT of the chest are presented in table 4. As compared to asthmatic patients, there was more severe-to-critical radiological presentation in the non-asthmatic patients.

\section{Management and outcomes}

As shown in table 5, 30 asthmatic patients (81\%) received oxygen, with high-concentration masks used in 10 patients. When nasal oxygen was used, the median oxygen flow rate was $2 \mathrm{~L} \cdot \mathrm{min}^{-1}$. In two patients, oxygen had to be maintained after discharge. 31 (84\%) received at least one antibiotic. SABA as needed was prescribed using a pressurised metered-dose inhaler with a spacer chamber, and previous inhaled treatments were maintained. Five patients received oral corticosteroids before admission, one of them in the context of self-medication. Three additional patients received intravenous corticosteroids during their hospital stay: refractory ARDS was the main cause of corticosteroid prescription in two cases, and bronchospasm occurring in the context of mechanical ventilation in one case. 11 patients were admitted to the ICU, six of them requiring invasive mechanical ventilation. There was a trend for more aged and comorbid patients among patients admitted to the ICU (table 6). A flowchart of the main outcomes is presented in figure 2. As shown in figure 3, asthmatic patients without multiple comorbidities were discharged home earlier.

Two deaths occurred at 1-month follow-up and one additional death was noted later, leading to a mortality rate of $8.1 \%$ in asthmatic patients (as compared to $14.6 \%$ in non-asthmatic patients; $\mathrm{p}=0.381$ ). The first patient was a 68-year-old woman treated for asthma by her pulmonologist with fluticasone/ salmeterol 500/50 $\mu \mathrm{g}$ daily (medium doses, GINA step 4). She had several comorbidities, including obesity (BMI $31.2 \mathrm{~kg} \cdot \mathrm{m}^{-2}$ ), diabetes, current chemotherapy for ovarian cancer, dyslipidaemia and sleep apnoea syndrome. At admission, no wheezing was reported; she was eosinopenic $\left(0\right.$ cells $\left.\cdot \mathrm{mm}^{-3}\right)$, had positive nasal SARS-CoV-2 RT-PCR and presented with mild extent of pulmonary lesions on CT of the chest. 5 days after symptoms had started, she was transferred to the ICU for acute respiratory failure. No acute pulmonary embolism was detected on CTPA. Due to an extremely poor prognosis, it was decided to restrict advanced life support, including intubation. She died on day 9.

The second patient was a 67-year-old woman with a diagnosis of asthma confirmed by a pulmonologist and treated with inhaled beclometasone/formoterol 200/12 $\mu \mathrm{g}$ daily (low doses, GINA step 3). She also displayed severe obesity (BMI $43 \mathrm{~kg} \cdot \mathrm{m}^{-2}$ ), hypertension, and renal failure requiring chronic dialysis and primary biliary cirrhosis. Mild wheezing was noted at admission, along with positive nasal SARS-CoV-2 RT-PCR, eosinopenia $\left(0\right.$ cells $\left.\cdot \mathrm{mm}^{-3}\right)$ and severe extent of pulmonary lesions on CT of the chest. 10 days after symptoms had started, she was intubated in the ICU for acute respiratory failure. She died at day 15 from refractory ARDS. 


\begin{tabular}{|c|c|c|c|}
\hline Characteristics & ICU & No ICU & p-value \\
\hline Patients n & 11 & 26 & \\
\hline Age years & $61(50-68)$ & $50(41-61)$ & 0.162 \\
\hline Male/female & $4(26) / 7(64)$ & $7(17) / 19(73)$ & 0.699 \\
\hline $\mathrm{BMI} \mathbf{k g} \cdot \mathrm{m}^{-2}$ & $29(28-32)$ & $28(25-31)$ & 0.144 \\
\hline \multicolumn{4}{|l|}{ Tobacco exposure } \\
\hline Current/former smokers & $3(27)$ & $9(35)$ & 1.000 \\
\hline Never-smokers & $8(73)$ & $17(65)$ & 1.000 \\
\hline \multicolumn{4}{|l|}{ Asthma management } \\
\hline No ICS & $2(18)$ & 10 (38) & 0.279 \\
\hline Low/medium-dose ICS & $4(36)$ & 10 (38) & 1.000 \\
\hline High-dose ICS & $5(45)$ & $6(24)$ & 0.244 \\
\hline Biological therapy (omalizumab) & $1(9)$ & $1(4)$ & \\
\hline Oral corticosteroids & 1 (9) & $0(0)$ & \\
\hline \multicolumn{4}{|l|}{ Comorbid conditions } \\
\hline Obesity $(\mathrm{BMI} \geqslant 30)$ & $5(45)$ & $8(31)$ & 0.465 \\
\hline Overweight $(25 \leqslant \mathrm{BMI}<30)$ & $6(55)$ & $12(46)$ & 0.728 \\
\hline Hypertension & $6(55)$ & $5(19)$ & 0.051 \\
\hline Diabetes & $1(9)$ & 6 (32) & 0.649 \\
\hline Renal failure & 1 (9) & $2(8)$ & 1.000 \\
\hline Coronary heart disease & $0(0)$ & $2(8)$ & 1.000 \\
\hline At least two of the six comorbidities & $7(64)$ & $8(31)$ & 0.080 \\
\hline
\end{tabular}

Data are presented as median (interquartile range) or $\mathrm{n}(\%)$, unless otherwise stated. The interquartile range is presented as first quartile - third quartile. BMI: body mass index; ICS: inhaled corticosteroid.

The third patient was a 75-year-old hypertensive and overweight woman (BMI $29.4 \mathrm{~kg} \cdot \mathrm{m}^{-2}$ ) treated for asthma with budesonide/formoterol $1200 / 36 \mu \mathrm{g}$ daily (high doses, GINA step 5). At admission to the emergency room, no wheezing was reported; she was eosinopenic $\left(0 \mathrm{cells} \cdot \mathrm{mm}^{-3}\right)$, had positive nasal SARS-CoV-2 RT-PCR and presented with very severe extent of radiological lesions (50-75\%). She was intubated 4 days later. Bronchospasm occurred during mechanical ventilation and systemic corticosteroids were administrated at day 12 . Withdrawal of mechanical ventilation was not possible and she died at day 45 from respiratory failure.
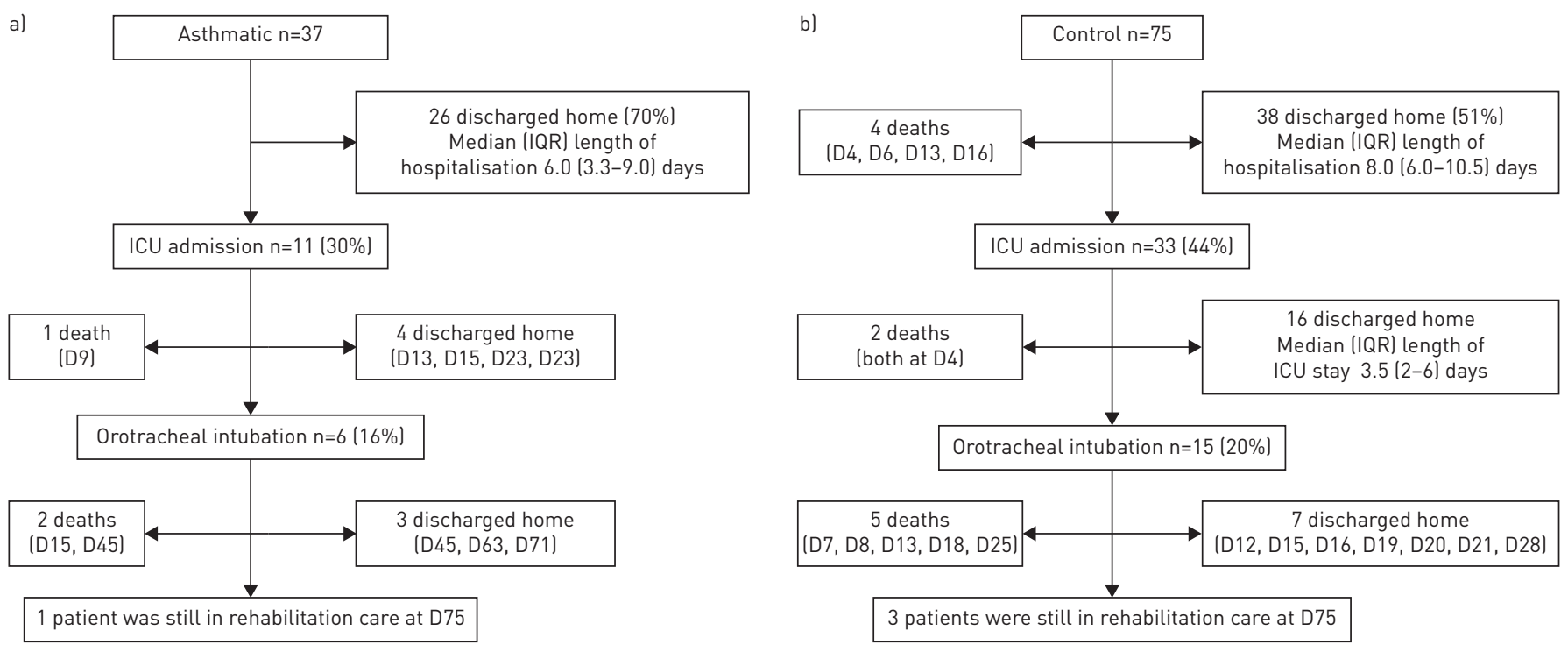

FIGURE 2 Outcomes of a) asthmatic and b) control patients with COVID-19 pneumonia. ICU: intensive care unit; D: day of death or discharge. 
FIGURE 3 Proportion of asthmatic patients discharged home over the first 30 days of hospitalisation, according to the number of their comorbidities.

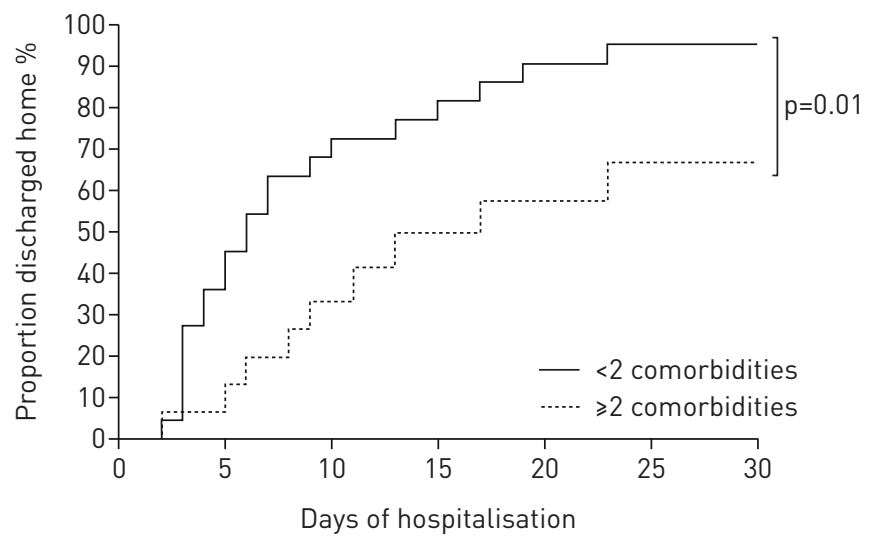

\section{Evolution of asthmatic patients treated with biologics}

Two patients were treated with anti-immunoglobulin E monoclonal antibody (omalizumab) for severe allergic asthma. The first was a 53-year-old woman treated with budesonide/formoterol 800/12 $\mu$ g daily, montelukast $10 \mathrm{mg} \cdot \mathrm{day}^{-1}$ and subcutaneous omalizumab at a monthly dose of $300 \mathrm{mg}$. She had no sign of asthma exacerbation before admission, but took a short course of oral prednisone $\left(40 \mathrm{mg} \cdot \mathrm{day}^{-1}\right)$ for 5 days as self-medication, which was stopped at admission. She had positive nasal SARS-CoV-2 RT-PCR, eosinopenia $\left(0\right.$ cells $\left.\cdot \mathrm{mm}^{-3}\right)$ and a moderate extent of lesions on CT of the chest. She had no evidence of asthma exacerbation or respiratory failure, allowing discharge home on day 5 .

The second patient was a 78-year-old overweight woman with severe allergic asthma and allergic bronchopulmonary aspergillosis, treated with budesonide/formoterol 800/12 $\mu \mathrm{g}$ daily, oral prednisone $5 \mathrm{mg} \cdot \mathrm{day}^{-1}$ and subcutaneous omalizumab $300 \mathrm{mg}$ twice monthly. She also suffered from hypothyroidism, lumbar spinal stenosis and depression. Initial presentation included crackles and minor wheezing, with positive nasal SARS-CoV-2 RT-PCR, blood eosinophil count of 50 cells $\cdot \mathrm{mm}^{-3}$ and severe extent of pneumonia on $\mathrm{CT}$ at admission (figure 4a). 9 days after the beginning of symptoms, she was admitted to the ICU for acute respiratory failure. Orotracheal intubation was needed and mechanical ventilation was well tolerated with no evidence of bronchospasm. After 8 days of mechanical ventilation, acute bronchospasm appeared for the first time. Aspergillus fumigatus was detected in bronchial secretions. Segmental acute pulmonary embolism was diagnosed 12 days after admission (figure $4 \mathrm{~b}$ ). Other treatments included anticoagulation, bronchodilator nebulisations, intravenous corticosteroids and voriconazole. The next omalizumab injection was administrated as planned, when she was under mechanical ventilation. No adverse events were observed and successful extubation was possible 5 days later. She was discharged from the ICU after 23 days. At day 75, she was well and alive, still undergoing rehabilitation.

\section{Discussion}

This prospective monocentric cohort describes clinical, biological and radiological characteristics and outcomes of asthmatic patients with COVID-19 pneumonia who required hospitalisation. During the
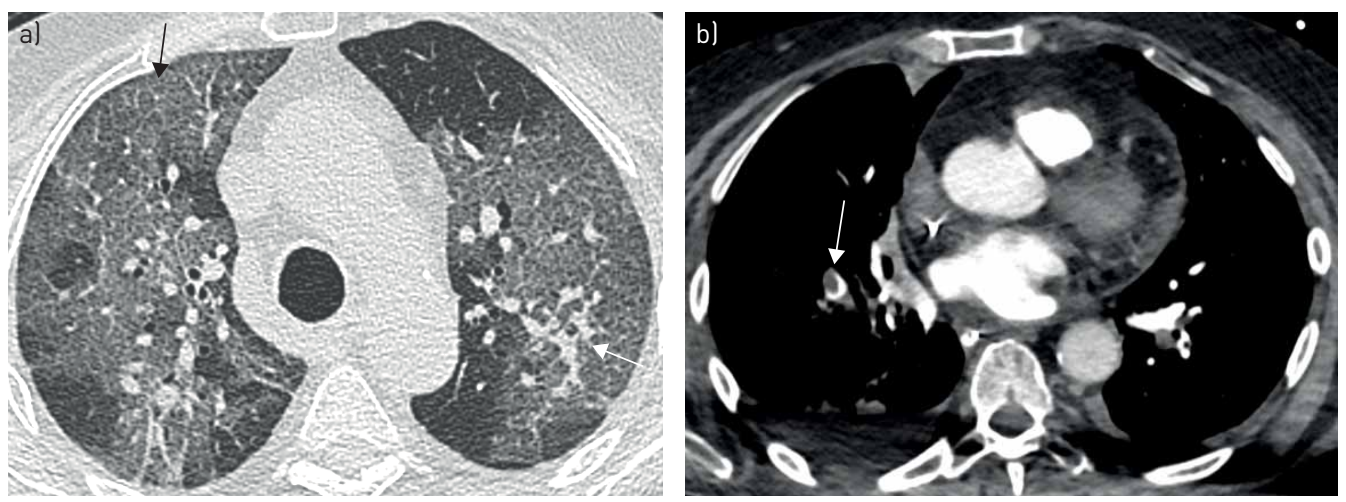

FIGURE 4 Computed tomography of the chest of a patient with severe allergic asthma at a) day 1 and b) day 12 of hospitalisation. a) Typical extended ground-glass opacities with crazy-paving pattern (black arrow) and nodular consolidations (white arrow). b) Computed tomography with pulmonary angiography revealing acute pulmonary embolism in the right lower lobe pulmonary artery (arrow). 
spring 2020 outbreak, asthmatic patients accounted for $<5 \%$ of total hospitalised patients in our institution. The most recent data available in France indicate that $6.4 \%$ of individuals have a current diagnosis of asthma [11]. In line with previous reports [12], our results suggest that asthmatic patients were thus not overrepresented among COVID-19 inpatients. In addition, no patient was hospitalised for a COVID-19-related asthma exacerbation during the outbreak and very few developed an asthma attack while hospitalised, which is consistent with data recently reported in Strasbourg, France [13]. This contrasts sharply with viral respiratory infections, including other types of coronavirus, being the main causes of asthma exacerbations [1].

Several mechanisms may explain this apparent paradox. First, a lower expression of SARS-CoV-2 cellular receptor angiotensin-converting enzyme 2 (ACE2) has been described in airway cells of patients with respiratory allergy and/or asthma, and it was also found that ACE2 expression was inversely associated with type 2 biomarkers [14]. Secondly, severe eosinopenia was a typical biological feature in our cohort, $78 \%$ of hospitalised asthmatic patients having no detectable blood eosinophils at admission. This finding is unusual in hospitalised asthmatic patients receiving neither systemic corticosteroids nor anti-interleukin-5 therapy. Similar findings were reported in a mostly non-asthmatic COVID-19 population in Wuhan, China, where eosinopenia was described in 53\% of hospitalised subjects [4] and in $81 \%$ of fatal cases [15]. As suggested by others [16], eosinopenia in COVID-19 may be a marker of more severe disease. In addition, one may speculate that it reflects a downregulation of type 2 inflammation that might decrease the risk of asthma exacerbation orchestrated by type 2 responses. Thirdly, it has been recently shown that severe COVID-19 is driven by an inappropriate inflammatory response, defined by low levels of type I and III interferons juxtaposed to elevated chemokines and high expression of interleukin-6, supporting the concept that reduced innate antiviral defences, coupled with exuberant pro-inflammatory cytokine production, are the defining and driving features of COVID-19 [17]. Further studies are needed, describing the cytokine profile of asthmatic patients in response to SARS-CoV-2 infection. Finally, there is in vitro evidence to support a protective effect of ICS on coronavirus infections [18]. Indeed, sputum analysis showed that ACE2 expression levels are significantly lower in asthma patients taking ICS than in those not taking ICS, especially when high doses are administered [19]. Randomised controlled trials are needed to test the effect of ICS on COVID-19 in both asthmatic and non-asthmatic patients.

We observed a female predominance (70\%) in our cohort, whereas previous studies have demonstrated an increased risk of SARS-CoV-2 infection in males [20]. This might be explained by age-related sex ratio differences, asthma being more prevalent in female adults [21, 22]. Moreover, obesity, hypertension and diabetes were the most common comorbidities observed in our cohort of hospitalised asthmatic patients with COVID-19, which is consistent with earlier research in other patient groups [5, 23]. Interestingly, obesity has been associated with asthma in women [24] and severe forms of COVID-19 in both sexes [25, 26].

Asthmatic patients with COVID-19 pneumonia who required hospitalisation presented with radiological characteristics similar to those described previously, with a predominance of peripheral ground-glass opacities [27]. Interestingly, three patients had a diagnosis of acute pulmonary embolism (8.1\%) on CTPA at admission or during hospitalisation. At the start of the COVID-19 outbreak, the first-line imaging tool in our centre relied on non-contrast CT of the chest [8]. However, more concern has been recently raised about thrombosis and pulmonary embolism in COVID-19 patients [28], underscoring that this complication may be more prevalent in this patient population.

Asthma therapy was unchanged in all patients, including biologics, as recommended by the French Asthma and Allergy Working Group (G2A) [29]. Interestingly, two patients were on omalizumab therapy prior to COVID-19. In one patient, the planned omalizumab injection was administered while she was under mechanical ventilation, experiencing severe bronchospasm and ARDS. No adverse events were observed and successful extubation was possible 5 days later.

Our study included a control group of COVID-19 pneumonia patients hospitalised in the same hospital during the same period. As compared to controls, asthmatic patients were younger, more likely to be female and tended to be less comorbid, which may explain, at least in part, the better outcomes in this population. However, it is interesting to note that mild pneumonia tended to be more frequent in asthmatic patients with higher doses of ICS (supplementary figure S2). Further studies are needed to investigate the possible positive effect of ICS on COVID-19 pneumonia as previously showed with dexamethasone in the RECOVERY trial [30]. The ongoing INHASCO trial (ClinicalTrials.gov, identifier number NCT04331054) is investigating this research question.

One of the study limitations is the relatively small number of asthmatic patients that were investigated. However, all patients were identified prospectively by an expert team of asthma specialists in a large university hospital hosting a severe asthma clinic, allowing systematic analysis of relevant information and meticulous follow-up. In a state of emergency, misdiagnoses of both asthma and COVID-19 cannot be 
excluded. Regarding asthma, it could be underdiagnosed, as diagnosis was based on self-report and pulmonary function tests could not be performed during the COVID-19 outbreak. Asthma might also be overdiagnosed, as previously reported in industrialised countries, especially in obese individuals [31]. Nevertheless, asthma diagnosis had been previously confirmed by a pulmonologist in $85 \%$ of cases. A COVID-19 overdiagnosis is also unlikely, with positive SARS-CoV-2 RT-PCR on nasopharyngeal swab in $84 \%$ of cases. RT-PCR was negative in only six patients who presented with a high clinical suspicion of COVID-19 and consistent CT of the chest during the outbreak [8].

In conclusion, our data indicate that asthmatic patients were not overrepresented in a large group of hospitalised pneumonia patients during the spring 2020 COVID-19 outbreak in Paris, France. In addition, COVID-19 pneumonia was not associated with asthma exacerbation at admission and at 1-month follow-up in patients who did not modify their asthma treatment, including those classified as GINA step 5 (high-dose ICS with LABA, low-dose oral corticosteroids, and long-term omalizumab). Large multicentre cohort studies are needed to confirm these data and explore the reasons why SARS-CoV-2 does not seem to trigger as many asthma exacerbations as previously seen with other respiratory viruses.

Acknowledgements: The authors thank the patients, their families, and all healthcare professionals and administrative staff from Hospital Bicêtre for their outstanding support. The authors thank the CRISALIS/F-CRIN network (Clinical Research Initiative in Severe Asthma: a Lever for Innovation \& Science).

Conflict of interest: A. Beurnier has nothing to disclose. E-M. Jutant has nothing to disclose. M. Jevnikar has nothing to disclose. A. Boucly has nothing to disclose. J. Pichon has nothing to disclose. M. Preda has nothing to disclose. M. Frank has nothing to disclose. J. Laurent has nothing to disclose. C. Richard has nothing to disclose. X. Monnet has nothing to disclose. J. Duranteau has nothing to disclose. A. Harrois has nothing to disclose. M-C. Chaumais has nothing to disclose. M-F. Bellin has nothing to disclose. N. Noël has nothing to disclose. S. Bulifon has nothing to disclose. X. Jaïs has nothing to disclose. F. Parent has nothing to disclose. A. Seferian has nothing to disclose. L. Savale has nothing to disclose. O. Sitbon reports grants, personal fees and non-financial support from Actelion Pharmaceuticals and MSD, personal fees from Acceleron Pharmaceuticals, Gossamer Bio and Ferrer, grants and personal fees from Bayer, grants from GlaxoSmithKline, outside the submitted work. D. Montani has nothing to disclose. M. Humbert reports grants, personal fees and non-financial support from GlaxoSmithKline, personal fees from AstraZeneca, Novartis, Roche, Sanofi and Teva, outside the submitted work.

\section{References}

1 Edwards MR, Bartlett NW, Hussell T, et al. The microbiology of asthma. Nat Rev Microbiol 2012; 10: 459-471.

2 Wang D, Hu B, Hu C, et al. Clinical characteristics of 138 hospitalized patients with 2019 novel coronavirus-infected pneumonia in Wuhan, China. JAMA 2020; 323: 1061-1069.

$3 \mathrm{Li}$ X, Xu S, Yu M, et al. Risk factors for severity and mortality in adult COVID-19 inpatients in Wuhan. J Allergy Clin Immunol 2020; 146: 110-118.

4 Zhang JJ, Dong X, Cao YY. Clinical characteristics of 140 patients infected with SARS-CoV-2 in Wuhan, China. Allergy 2020; 75: 1730-1741.

5 Goyal P, Choi JJ, Pinheiro LC, et al. Clinical characteristics of COVID-19 in New York City. N Engl J Med 2020; 382: 2372-2374.

6 Agence Régionale de Santé Île-de-France. Coronavirus (COVID-19): points de situation pour la région Île-de-France [Coronavirus (COVID-19): situation points for the region Île-de-France]. www.iledefrance.ars.sante. fr/coronavirus-covid-19-points-de-situation Date last updated: 15 March 2020. Date last accessed: 12 May 2020

7 Santé Publique France. COVID-19: point épidémiologique du 16 avril 2020 [COVID-19: epidemiological update for 16 April 2020]. www.santepubliquefrance.fr/maladies-et-traumatismes/maladies-et-infections-respiratoires/ infection-a-coronavirus/documents/bulletin-national/covid-19-point-epidemiologique-du-16-avril-2020 Date last updated: 18 April 2020. Date last accessed: 12 May 2020.

8 Rubin GD, Ryerson CJ, Haramati LB, et al. The role of chest imaging in patient management during the COVID-19 pandemic: a multinational consensus statement from the Fleischner Society. Chest 2020; 158: 106-116.

9 Global Initiative for Asthma (GINA). Global Strategy for Asthma Management and Prevention. 2020. Available from: http://ginasthma.org/

10 Konstantinides SV, Meyer G, Becattini C, et al. 2019 ESC Guidelines for the diagnosis and management of acute pulmonary embolism developed in collaboration with the European Respiratory Society (ERS). Eur Respir J 2019; 54: 1901647.

11 Raherison-Semjen C, Izadifar A, Russier M, et al. Prévalence et prise en charge de l'asthme de l'adulte en France en 2018: enquête ASTHMAPOP [Asthma prevalence and management in adults in France in 2018: ASTHMAPOP survey]. Rev Epidemiol Santé Publique 2019; 67: S179.

12 Halpin DMG, Faner R, Sibila O, et al. Do chronic respiratory diseases or their treatment affect the risk of SARS-CoV-2 infection? Lancet Respir Med 2020; 8: 436-438.

13 Grandbastien M, Piotin A, Godet J, et al. SARS-CoV-2 pneumonia in hospitalized asthmatic patients did not induce severe exacerbation. J Allergy Clin Immunol Pract 2020; 8: 2600-2607.

14 Jackson DJ, Busse WW, Bacharier LB, et al. Association of respiratory allergy, asthma, and expression of the SARS-CoV-2 receptor ACE2. J Allergy Clin Immunol 2020; 146: 203-206.

$15 \mathrm{Du} \mathrm{Y}$, Tu L, Zhu P, et al. Clinical features of 85 fatal cases of COVID-19 from Wuhan. A retrospective observational study. Am J Respir Crit Care Med 2020; 201: 1372-1379.

16 Lindsley AW, Schwartz JT, Rothenberg ME. Eosinophil responses during COVID-19 infections and coronavirus vaccination. J Allergy Clin Immunol 2020; 146: 1-7.

17 Blanco-Melo D, Nilsson-Payant BE, Liu WC, et al. Imbalanced host response to SARS-CoV-2 drives development of COVID-19. Cell 2020; 181: 1036-1045. 
18 Halpin DMG, Singh D, Hadfield RM. Inhaled corticosteroids and COVID-19: a systematic review and clinical perspective. Eur Respir J 2020; 55: 2001009.

19 Peters MC, Sajuthi S, Deford P, et al. COVID-19-related genes in sputum cells in asthma. Relationship to demographic features and corticosteroids. Am J Respir Crit Care Med 2020; 202: 83-90.

20 Chen N, Zhou M, Dong X, et al. Epidemiological and clinical characteristics of 99 cases of 2019 novel coronavirus pneumonia in Wuhan, China: a descriptive study. Lancet 2020; 395: 507-513.

21 Schatz M, Camargo CA Jr. The relationship of sex to asthma prevalence, health care utilization, and medications in a large managed care organization. Ann Allergy Asthma Immunol 2003; 91: 553-558.

22 Zein JG, Denson JL, Wechsler ME. Asthma over the adult life course: gender and hormonal influences. Clin Chest Med 2019; 40: 149-161.

23 Guan WJ, Liang WH, Zhao Y, et al. Comorbidity and its impact on 1590 patients with COVID-19 in China: a nationwide analysis. Eur Respir J 2020; 55: 2000547.

24 Chen Y, Dales R, Tang M, et al. Obesity may increase the incidence of asthma in women but not in men: longitudinal observations from the Canadian National Population Health Surveys. Am J Epidemiol 2002; 155: 191-197.

25 Simonnet A, Chetboun M, Poissy J, et al. High prevalence of obesity in severe acute respiratory syndrome coronavirus-2 (SARS-CoV-2) requiring invasive mechanical ventilation. Obesity 2020; 28: 1195-1199.

26 Sattar N, McInnes IB, McMurray JJV. Obesity is a risk factor for severe COVID-19 infection: multiple potential mechanisms. Circulation 2020; 142: 4-6.

27 Shi $\mathrm{H}$, Han X, Jiang N, et al. Radiological findings from 81 patients with COVID-19 pneumonia in Wuhan, China: a descriptive study. Lancet Infect Dis 2020; 20: 425-434.

28 Bompard F, Monnier H, Saab I, et al. Pulmonary embolism in patients with COVID-19 pneumonia. Eur Respir J 2020; 56: 2001365.

29 Société de Pneumologie de Langue Française (SPLF). Position of the Asthma and Allergy Working Group (G2A) of the SPLF on the management of asthma patients during the COVID-19 epidemic. http://splf.fr/wp-content/ uploads/2020/04/COVID-asthma_CRISALIS-EN.pdf Date last updated: April 2020. Date last accessed: 16 May 2020.

30 Horby P, Lim WS, Emberson J, et al. Effect of dexamethasone in hospitalized patients with COVID-19: preliminary report. medRxiv 2020; preprint [https://doi.org/10.1101/2020.06.22.20137273].

31 Aaron SD, Vandemheen KL, Boulet LP, et al. Overdiagnosis of asthma in obese and nonobese adults. CMAJ 2008; 179: 1121-1131. 